\title{
GABRIEL TRUJILLO MUÑOZ: ESCRITOR, EDITOR Y ESTUDIOSO DE LA CIENCIA FICCIÓN MEXICANA
}

Samuel Manickam

\section{(9) $\mathbb{D} \Theta \Theta$}

Esta obra está bajo una licencia Creative Commons

Reconocimiento-No Comercial-Sin Obra Derivada 



\title{
GABRIEL TRUJILLO MUÑOZ: ESCRITOR, EDITOR Y ESTUDIOSO DE LA CIENCIA FICCIÓN MEXICANA
}

\author{
GABRIEL TRUJILLO MUÑOZ: WRITER, EDITOR, AND RESEARCHER \\ OF MEXICAN SCIENCE FICTION
}

\author{
Samuel Manickam
}

\begin{abstract}
RESUMEN
En la ciencia ficción mexicana contemporánea Gabriel Trujillo Muñoz es uno de los protagonistas más destacados. Desde hace más de treinta años este autor mexicalense ha promovido y difundido este género literario en México por medio de cuentos, novelas, antologías y estudios críticos. En este artículo se hará un recorrido de las obras cienciaficcioneras más relevantes de Trujillo, empezando con sus cuentos y terminando con sus monografías.

Palabras clave: ciencia ficción, cuento, novela, antología, estudio crítico.
\end{abstract}

\begin{abstract}
Gabriel Trujillo Muñoz is one of the most important figures in contemporary Mexican science fiction. For more than thirty years this author and scholar from Mexicali has raised the visibility of this literary genre in Mexico through stories, novels, anthologies and critical studies. This article provides a panoramic overview of this author's most relevant works, from his stories to his monographs.
\end{abstract}

Key words: science fiction, short story, novel, anthology, critical study.

Aunque la ciencia ficción mexicana tiene una larga trayectoria que se remonta al siglo XVIII, es sólo en las décadas recientes que se ha vuelto un objeto de estudio serio por parte de los académicos. En 1977 Ross Larson publica su libro precursor Fantasy and Imagination in the Mexican Narrative en el cual provee una indagación tentativa pero valiosa sobre la literatura mexicana que se desvía de la vertiente realista, y en este libro incluye un capítulo sobre la ciencia ficción también. Sin embargo, aunque la producción de la ciencia ficción mexicana ha aumentado con creces desde los años ochenta del siglo anterior, no había estudios detallados sobre este género literario por parte de los mismos mexicanos hasta los últimos años del siglo XX. Federico Schaffler González, Miguel Ángel Fernández Delgado y Ramón López

Dr. Samuel Manickam. University of North Texas. Profesor Asociado de Español. Estados Unidos. Correo electrónico: manickam@unt.edu

Recepción: 14- 03- 2014

Aceptación: 09- 04- 2014 
Castro son algunos de los estudiosos y promovedores más dedicados de la ciencia ficción mexicana en las últimas dos décadas, y Gabriel Trujillo Muñoz (Mexicali, Baja California, 1958) es miembro clave de este elenco ilustre. No obstante, lo que asombra de este último es su dedicación incansable a este género literario en todos los ámbitos -como estudioso, como escritor y como editor- por lo cual es preciso realizar un aprecio panorámico de los varios aportes de este escritor mexicalense que se esfuerza por hacer lucir la ciencia ficción mexicana y así alimentar entusiasmo por la misma.

Antes de continuar, cabe proveer una definición de la ciencia ficción. Se sabe que este género literario se asocia con los países europeos y los EEUU donde nació en el siglo XIX durante la Revolución Industrial, y que hoy en día se encuentra esparcido en la literatura mundial. Obras fundadoras de la ciencia ficción incluyen Frankenstein (1818) de Mary Shelley, De la tierra a la luna (1864) de Julio Verne y La guerra de los mundos (1898) de H.G. Wells (aunque se podrían señalar antecedentes literarios que se remontan hasta antes de la época cristiana, y que se podrían denominar como "proto-ciencia ficción"). La ciencia ficción es un producto literario de una sociedad rápidamente transformada por los milagros tecnológicos y, como tal, tiende a expresar una actitud crítica hacia la nueva vida moderna donde las máquinas protagonizarán un papel imprescindible en la vida cotidiana. Aunque existe una multitud de teóricos que han aportado sus observaciones sobre los muchos aspectos de este género literario, aquí bastará la definición sucinta pero inclusiva de Kingsley Amis para quien la ciencia ficción es esa clase de narrativa que emplea como premisa alguna innovación hipotética de la ciencia o la tecnología, que sea de origen humano o extraterrestre (Amis, 1976, p. 11). Dicha tecnología novedosa puede ser algo asombroso, como una máquina de tiempo, o algo más mundano, como una pluma que tiene tinta borrable. La clave es su impacto en nuestra existencia cotidiana. La definición de la ciencia ficción que ofrece Trujillo-Muñoz no varía mucho de la de Amis: "El género literario que se encarga de contar lo imposible como plausible, que nos ofrece una visión del mundo desde los avances tecnológicos y su impacto en el ser humano y la sociedad” (Trujillo-Muñoz, “QQué me inspiró...?”, inédito). Para nuestro autor la ciencia ficción no es simplemente un pasatiempo literario sino una manera de observar y comprender mejor el mundo, pues dice:

\footnotetext{
La otredad, lo numinoso, lo maravilloso, lo intangible me interesa o me sirve de contrapeso frente a mi perspectiva analítica, científica a la Karl Popper. Dudo de la realidad y dudo de la fantasía, por eso me siento tan en casa en géneros como la ciencia ficción (por su unión de la cultura científica con la humanística) [...]. (Fallon, 2002a, p. 92)
}

La ciencia ficción ofrece un vuelo imaginativo, no tanto para escaparse del mundo material como para adentrarlo de manera más profunda. En esta exposición y análisis de la obra cienciaficcionera de Trujillo-Muñoz seguiré de forma cronológica su involucramiento paulatino con este género literario en que comenzó como un escritor desconocido de cuentos ocasionales pero en la que terminó volviéndose un apasionado cronista, estudioso y defensor incansable del mismo. Está de más aclarar que en este espacio limitado no se podrán abarcar todas las obras de Trujillo-Muñoz sino sólo las más destacadas.

A nuestro autor siempre le ha llamado la atención la ciencia ficción. En su adolescencia era aficionado de autores ya clásicos del canon literario europeo y estadunidense, tales como H.G. Wells, Julio Verne, Issac Asimov y Ray Bradbury, entre muchos otros. A partir de 1981, a los veintitrés años, Trujillo-Muñoz empieza a escribir y publicar sus primeros relatos de ciencia ficción al involucrarse con escritores norteños que comparten este afán literario. Antes 
de indagar de manera profunda en la ciencia ficción nacional, Trujillo Muñoz decide estudiar las raíces y la evolución de este género en Europa y EEUU en La ciencia ficción. Literatura y conocimiento (1991), estudio que fue galardonado con el Premio de Literatura en Baja California. Con lenguaje sencillo (rasgo esencial de su estilo erudito) el autor nos ofrece un repaso por los teóricos principales (i.e. Suvin, Todorov, Asimov, etc.) así como los antecedentes literarios de los cuales la ciencia ficción se alimenta (i.e. la fantasía, la utopía, el romance, etc.). Como comenta Ilán Stavans, "que un estudio como éste sea producido en español es considerado casi un triunfo de una determinante fuerza de voluntad" (Stavans, 2002, p. 201). Aunque con este estudio Trujillo-Muñoz no abre terreno erudito que no haya sido descubierto ya por otros teóricos mucho antes que él en Europa y los EEUU, este libro sirve bien al público hispanohablante como una introducción al fenómeno de la ciencia ficción. También, al realizar este estudio Trujillo-Muñoz se enseña a sí mismo sobre esta rama de literatura, preparación que le servirá de base sólida desde la cual se lanzará al área casi desconocida en aquel entonces de la ciencia ficción mexicana. Su interés creciente en este género literario en español se nota en la penúltima sección intitulada "La ciencia ficción latinoamericana" donde nuestro autor habla de los practicantes más tempranos (i.e. Pedro Castera, Eduardo Ladislao Homberg, Amado Nervo, etc.), pasando por los del medio siglo XX (Jorge Luis Borges, Adolfo Bioy-Casares, Hugo Correa, etc.) y terminando con algunos contemporáneos (i.e. Angélica Gorodischer, Carlos Olvera, Alfredo Cardona-Peña, etc.). Quizá falta que el autor profundice más en sus análisis de las varias obras que menciona con aparente prisa, y que añada otros autores, sin embargo, en este breve ensayo Trujillo-Muñoz nos presenta una pauta general que, a estas alturas del siglo XXI, aparecerá como un momento de parte aguas ya que desde entonces varios estudiosos de este género en América Latina han venido rellenando los huecos de información, aunque aún queda mucho por descubrir.

En el mismo año en que publica su primer estudio sobre la ciencia ficción también produce Miríada (1991), una colección de nueve cuentos, algunos previamente publicados. Aclara el autor en el prefacio de este libro que "Este doble origen - la ciencia ficción y la narrativa fantástica - ha sido la piedra de toque de mis propios relatos" (Trujillo-Muñoz, 1991b, p. 10). Así, nuestro autor aquí sigue más las huellas de Frank Herbert, que imagina otros mundos fantásticos informados por la tecnología, que las de Arthur C. Clarke, para quien la innovación tecnológica es el punto de partida. Empleando un lenguaje nítido que a veces puede llegar a ser barroco en su afán por las explicaciones detalladas y desbordantes -que sea un narrador omnisciente describiendo un mundo ajeno a nuestra realidad o un personaje exponiendo sobre el funcionamiento de algún proceso técnico- Trujillo-Muñoz transporta al lector a una gama de posibles existencias cuyas situaciones problemáticas, como en toda ciencia ficción, nos son familiares. Como observa Humberto Félix Berumen, "Son cuentos de un minucioso cuidado, atento a todos los detalles que contribuyen a urdir con habilidad una historia de interés general y no sólo para unos cuantos" (Berumen, 2002c, p. 208). Si a veces falta el toque irónico o humorístico en estos cuentos para un lector bien entrado en la ciencia ficción clásica, esto se compensa con la rica imaginación trujillana.

En casi todos los cuentos el resorte de la trama se basa en mundos misteriosos donde se encuentra alguna tensión o rompecabezas que resolver. En "Man-This-Bei” un exiliado político en algún planeta a que no sabe cómo llegó es seducido por una mujer que luego tiene que matarlo; resulta que se usan las víctimas como él para alimentar a los bebés en este planeta. En "Invocaciones" un guerrero se acerca a un templo misterioso -que recuerda de una 
pirámide maya- vigilado por una guardiana. El guerrero la mata porque dice que el templo será re-dedicado a un nuevo dios, pero en un giro irónico (que puede recordar de "Las ruinas circulares" de Borges) resulta que su verdadera misión ha sido servir al dios que aún reside allá. En "Canción de mar distante", el cuento mejor acabado en esta colección, el narrador, un hombre cuya edad se mide en siglos, se encuentra en Aguaria, un planeta constituido casi completamente por agua. Aparentemente este mar es un ser consciente e inteligente que ha matado a dos de sus compañeros. Nayla, una muchacha que él conoció hace siglos, reaparece y lo engatusa para que lo siga a las profundidades marinas donde por fin se resolverá este misterio. Ahora bien, cualquier lector dedicado de la ciencia ficción se percatará de que este cuento debe mucho a Solaris (1961) de Stanislaw Lem, novela llamativa por su concepción de un extraterrestre (el mar) que no es antropomórfico, y Trujillo-Muñoz es el primero en reconocer esta deuda ya que incluye una cita de dicha novela como epígrafe. No obstante, al reinventar esta historia para nosotros en la lengua castellana este autor nos obsequia un deleite literario.

Si el misterio que resolver en los cuentos ya mencionados es a veces al nivel personal, en la mayoría de los casos el mundo ha sufrido una catástrofe, o está por sufrir una. Es decir, a nuestro autor le gusta acudir al apocalipsis -temática predilecta de la ciencia ficción- para crear la tensión necesaria en estos cuentos. En "Una cierta niebla", la ciudad de Tushra ha desaparecido por razones desconocidas, y en sus ruinas en el desierto no hay ningún rastro de vida. Se habla de un "fuego universal" que se podría interpretar como una explosión nuclear. También, una neblina fatal que mata a todos en su camino es probablemente una nube radioactiva. Los personajes viven en un mundo pos-apocalíptico donde el pasado se ha vuelto tan intangible como la neblina. En "La máscara de Isilder" una civilización que recordará de la época medieval europea se encuentra amenazada por los fuegos arrasadores de un volcán, una "fuente atómica natural" (Trujillo-Muñoz, 1991b, p. 28). Hay una máscara heredada de las civilizaciones antiguas que protegerá al portador de los fuegos mortales. Arvald, el héroe, se la pone para salir a enfrentar las llamas gigantescas y logra controlarlas, y así el apocalipsis queda esquivado. Para estos habitantes la máscara se vale de características mágicas, pero la verdad implícita es que es un invento de una civilización tecnológicamente avanzada. Es decir, en éste como en otros cuentos, lo que a nosotros en el mundo moderno nos parecerán aparatos maravillosos pero que cuentan con una explicación lógica basada en la ciencia (i.e. el iPhone, el automóvil, el avión) serían para los habitantes de mundos menos avanzados en materia tecnológica objetos verdaderamente mágicos. En un giro irónico, estos mundos antiguos muchas veces quedan en nuestro futuro, y no en nuestro pasado, o sea, algún evento catastrófico ha reducido las grandes civilizaciones a pueblos primitivos donde los sobrevivientes ya no cuentan con memoria colectiva de las civilizaciones del pasado más avanzadas.

En "Pesadilla", el cuento que cierra esta colección, Trujillo-Muñoz acude a la historia mexicana al retratar la situación apocalíptica en términos de la conquista española de Mesoamérica. Sin embargo, el año es 2092 y no 1521, y los EEUU ha decaído como una superpotencia mientras que Europa ha recobrado su papel de invasor de tierras lejanas. Así, la meta de España es reconquistar sus territorios americanos. En medio de esta batalla que dura cinco años, de repente el protagonista se encuentra con Hernán Cortés y su séquito de hombres, es decir, es transportado al siglo XVI. Pero no se define a ciencia cierta cuál es el tiempo verdadero en el cuento ya que el protagonista sufre de pesadillas durante sus largas horas de sueño profundo (y en este aspecto nos recuerda de "La noche boca arriba" de Cortázar). 
En un final abierto y ambiguo la guerra seguirá, que sea contra los españoles medievales o modernos, pues estos luchadores mexicanos no se dejarán vencer fácilmente. Lo atrayente de este cuento, a diferencia de los otros en Miríada, es que al arraigarlo en la historia mexicana, Trujillo-Muñoz nos proporciona un relato que podría llamarse "ciencia ficción mexicana" en un sentido más autóctono. Es decir, a mi ver, en las más llamativas obras de la ciencia ficción mexicana los autores maniobran de manera creativa este género ya universal para comentar sobre la historia, la cultura, la sociedad y la política mexicana. ${ }^{1}$ Es una tarea que TrujilloMuñoz comienza a realizar en Miríada, y que encuentra su plena resolución unos años después en la novela Espantapájaros.

Pero nuestro autor coloca su primera novela de ciencia ficción, Laberinto (As time goes by) (1995), en una época futura desprovista de una historia nacional específica. Ganadora del Premio Estatal de Novela en 1994 (Baja California), es una obra admirable tanto por su propuesta filosófica como por su estructura polifónica. Como observa Berumen, las "mayores virtudes" de esta novela son "la agilidad narrativa, la eficaz construcción de su argumento y una rigurosa organización de su estructura" (Berumen, 2002a, p. 294). A propósito de la estructura, al colocar Trujillo-Muñoz un arquetipo mitológico antiquísimo, el laberinto, que también tiene su resonancia literaria latinoamericana por medio de Paz y Borges, como el objeto central de esta novela, Trujillo-Muñoz nos ofrece un paradigma para el significado, o los significados, de la vida misma. En este sentido, Laberinto es una disquisición filosófica que se aprovecha de las herramientas ofrecidas por la ciencia ficción. En esta novela un experimento científico pretende "crear túneles en la madeja espacio-temporal donde se pudieran comunicar los universos múltiples que existen a la vez", sin embargo, una alteración inesperada llamada “derridación" "puso en caos total a la civilización humana" (Trujillo-Muñoz, 1995, pp. 22-23) a partir del año 2078, y dura por cuatro décadas antes de que el estado "normal" se reponga. Durante este período de caos histórico un dictador alemán llamado Hans Boder se aprovecha de la confusión para promover e imponer su filosofía discriminatoria y divisoria llamada el “proyecto Klux" (Trujillo-Muñoz, 1995, p. 78). Cuando se acaba la derridación, Boder se esconde dentro de un laberinto que ha inventado. Pero este laberinto resulta ser "una especie de archivo multimodal del inconsciente arquetípico de la humanidad" (Trujillo-Muñoz, 1995, p. 23), es decir, Boder queda perdido y tal vez confundido en su propio invento. Dentro del laberinto se aventura una banda de guerreros encabezada por una mujer, Anastasia Dax, para capturar al dictador alemán y hacer estallar esta estructura, meta que logran. Sin embargo, por encontrarse dentro del laberinto donde todo se puede volver relativo, Boder ya no es un dictador malévolo. Como dice un científico, "Boder es tan inocente como usted o como yo. El es sólo una posibilidad criminal a futuro" (Trujillo-Muñoz, 1995, p. 137). En la actualidad en el año 3820, la vida que llevan los humanos es "multidimensional" caracterizada por "un mestizaje continuo" (Trujillo-Muñoz, 1995, p. 140); aparentemente los humanos han superado las divisiones étnicas y raciales para lograr una sociedad sumamente inclusiva, o sea, una utopía.

El aspecto que más llama la atención en esta novela es la estructura narrativa. Dos segmentos de narrativa van intercalándose a lo largo de la obra: el primero es un relato sobre los personajes dentro del laberinto y la búsqueda por Boder, y el segundo es una serie de citas provenientes de varias fuentes que indagan sobre la naturaleza de la derridación e informan al lector sobre el origen del laberinto y Boder. Mientras que el primer hilo narrativo es una aventura de pura ciencia ficción de carácter popular, el segundo ofrece una variedad de voces y tonalidades de índole más literaria, y en este sentido vuelve la novela en un texto más abierto 
debido a la polifonía. Por ejemplo, a pesar de la explicación enciclopédica de la derridación (citada arriba), no existe un consenso ni respecto al significado ni a las implicaciones de este fenómeno caótico. Alfredo Peña, por ejemplo, declara que "la derridación no es un cambio total, sino una metamorfosis estable" (Trujillo-Muñoz, 1995, p. 46). Jacobo Hart opina que "La derridación nos ofrece la posibilidad de contemplar lo sagrado tal como lo sagrado: un caos que nos envuelve, un furor que nos conmociona, el éxtasis que canta desde nuestro ser al mundo" (Trujillo-Muñoz, 1995, p. 48). Y Jeremías Atonal ve la derridación como "una magnífica oportunidad para la catarsis y el autoconocimiento" (Trujillo-Muñoz, 1995, p. 100). Como observa un reseñista de esta novela, "the variety of interpretations and perspectives they reveal signal that all histories are multifaceted and incomplete, be they encyclopedias, songs or secret diaries" (Fallon, 2002b, p. 380). Es decir, nuestro autor nos presenta una novela abierta que ofrece muchas lecturas sin agotar fácilmente las posibilidades. Esta apertura textual señala bien la filosofía de libre pensamiento a que se aferra Trujillo-Muñoz, y para quien el acto de leer es una defensa "frente a los dogmas de la fe que prohíben cualquier desviación o discusión de las normas establecidas, frente al fascismo que no quiere vivir sino controlar" (EspinozaGalindo, 2002, p. 12). En esta novela el fascismo es claramente representado por el dictador Boder mientras que el laberinto simboliza la posibilidad de libre pensamiento de un individuo. Por fin, cabe notar que aunque las dos secciones intercaladas se complementan, a mi ver la segunda, constituida por varias citas, hace lucir mejor el talento literario de nuestro autor por el lenguaje acabado que a veces llega a ser poético. Es tan marcada la diferencia del lenguaje entre los dos segmentos que casi parecen escritos por dos autores distintos, lo cual muestra el alcance del genio literario de Trujillo-Muñoz. ${ }^{2}$

Nuestro autor ubica su segunda novela de ciencia ficción, Espantapájaros (1999), finalista para el prestigioso Premio UPC (Universidad Politécnica de Cataluña), en un área geográfica que le es mucho más familiar -la región fronteriza entre México y los EEUU-. Sobre esta área muy alejada de la ciudad letrada mexicana por excelencia, México, D.F., Trujillo Muñoz dice: "es una zona franca, un territorio poroso por donde todo -ideas, personas, productos- se cuela sin dejar más rastro que las leyendas de su cruce, que la memoria colectiva de sus respectivos espejismos" (Trujillo-Muñoz, "La ciencia ficción mexicana", inédito). Si el mestizaje cultural y lingüístico es un aspecto definitorio de la frontera entonces, como en la novela anterior, aquí también se nota una afirmación de lo mestizo, lo cultural y biológicamente híbrido. En Espantapájaros un equipo de científicos estadounidenses trabajan en laboratorios secretos en Nuevo México para inventar una criatura sofisticada que será el producto de la "unión entre lo animal y lo humano" (Trujillo-Muñoz, 1999b, p. 45). Esta novedad biológica, denominada GRACO (acrónimo de Genetic Research for Animal Conscience and Operativity) cuenta con la habilidad de volar y así volverse espía y soldado en situaciones bélicas. Es decir, es un producto de la industria armamentista estadounidense. No obstante, los gracos logran escaparse y reproducirse, y después franquean la frontera para establecerse en México donde se vuelven una especie de ayuda divina para los inmigrantes que intentan llegar a los EEUU.

En esta novela Trujillo-Muñoz se vale de un lenguaje más simple de "best-seller" para describir en pinceladas rápidas el desenvolvimiento de una historia de suspenso aventurero que nos recuerda de un libro de Michael Crichton, Parque Jurásico (1990). Pero mientras Crichton se contenta con simplemente explorar una premisa científica (la posibilidad de revivir a los dinosaurios), Trujillo-Muñoz va más allá de lo estrictamente científico (o seudocientífico) para explorar el aspecto sociocultural de un invento biológico. Los científicos 
en Espantapájaros erran cuando asumen que los gracos serán máquinas de espionaje y matanza sin propia voluntad, una especie de "drone", pues resulta que no sólo cuentan con la habilidad de pensar racionalmente sino que son muy astutos para sobrevivir fuera de su lugar de nacimiento. Conocen estrategias de guerra para confundir y evadir a sus perseguidores, y como hermafroditas son capaces de producir hasta cuatro camadas de gracos por año, incrementando de esta manera su población. En la frontera aprenden español en poco tiempo para poder comunicarse en el país vecino. Una vez en México se adaptan al nuevo ambiente y en lugar de seguir dependiendo de la sangre de sus víctimas para sobrevivir, prescinden de esta necesidad al mismo tiempo que se vuelven ayudantes de los inmigrantes que desean llegar al "norte". Sin embargo, se mantienen alejados, volviéndose criaturas misteriosas y míticas para el público mexicano. Así, al final estas criaturas calificadas de "monstruos" en los EEUU son vistas como santos en México; lo que en un principio es un arma para proteger las fronteras estadounidenses se vuelve un arma para violar las mismas fronteras. También, se reconoce, a nivel mundial la cualidad híbrida de los gracos que trascienden los límites nacionales en un sentido literal y metafórico al ser reconocidos por la ONU, aunque "las grandes religiones constituidas siguen debatiendo si los gracos tienen alma o ésta es sólo un atributo humano" (Trujillo-Muñoz, 1999b, p. 151). Como observa Heriberto Yépez, esta novela está escrita "como un guión de la serie X-Files pero termina como un declarado indígena” (Yépez, 2002, p. 327). No obstante, un aspecto un tanto negativo de la novela es la representación de los mexicanos que suelen ser o narcotraficantes malévolos o inmigrantes sencillos, pues así el autor perpetúa estereotipos comunes. Todos los científicos, en cambio, son estadounidenses, y aun hay un tal General Duloth que empieza a simpatizar con los gracos y, por consiguiente, es encarcelado de manera heroica. Trujillo-Muñoz podía haber aprovechado de su gran imaginación para retratar personajes mexicanos que sean científicos o aun periodistas o detectives que desafían la versión oficial de estos "chupacabras", así mostrando que en México también existe tanto la inquisición científica.

Después de incursionar en la ciencia ficción por medio de cuentos y novelas durante la primera mitad de los años noventa del siglo pasado, Trujillo-Muñoz edita una antología de ciencia ficción mexicana intitulada El futuro en llamas (1997). Este libro es evidencia irrefutable de no sólo su gran conocimiento de este género en las letras mexicanas sino también muestra su afán desinteresado por promover los escritos cienciaficcioneros de sus compatriotas, tanto los antepasados como los contemporáneos. Cabe notar que ésta no es la primera antología de ciencia ficción mexicana pues Federico Schaffler-González ya había editado los tres volúmenes de Más allá de lo imaginado: Antología de la ciencia ficción mexicana entre 1991 y 1994. Sin embargo, mientras que Schaffler-González se enfoca en escritores actuales, con frecuencia desconocidos, una meta valiosa, Trujillo-Muñoz decide remontarse a las épocas anteriores para recuperar "cuentos clásicos de la ciencia ficción mexicana", como señala el subtítulo de su antología. En la introducción nuestro autor delinea una "crónica" de la ciencia ficción mexicana donde describe las varias etapas y corrientes literarias así como autores principales, comenzando con Manuel Antonio de Rivas y terminando con los contemporáneos como Mauricio-José Schwarz y Arturo César Rojas. También, en la introducción nos provee un breve repaso de los orígenes de este género en Europa y los EEUU. Aunque no ofrece una definición precisa de qué es la ciencia ficción, tarea esencial en un libro de esta índole, nos dice para qué sirve este género literario: "para dedicarse a explorar al ser humano que somos, al universo al filo de la navaja en que vivimos, a la sociedad que nos refleja y a la que reflejamos en cada uno de nuestros sueños, 
en cada una de nuestras pesadillas" (Trujillo-Muñoz, 1997, p. 10). Lo admirable de esta antología es que arma para el público general una colección de relatos imprescindibles que muestran sin lugar a dudas la variedad de la ciencia ficción de alta calidad producida en México a lo largo de tres siglos. Respecto a los dieciocho cuentos aquí incluidos, es una lástima que se ofrece sólo una versión simplificada y acortada del cuento famoso de fray Manuel Antonio de Rivas, "Sizigias y cuadraturas lunares" (1775), ${ }^{3}$ el relato más antiguo de la ciencia ficción latinoamericana (desenterrado por el historiador Pablo González-Casanova en el Archivo General de la Nación en los años cincuenta). En 1994 Ana María Morales, de El Colegio de México, publica una excelente transcripción paleográfica fiel al manuscrito original de este relato; de haber utilizado una versión editada de dicha transcripción aquí, se podría apreciar mejor el lenguaje original de la época colonial en que fue escrito este cuento fundador de la ciencia ficción mexicana. ${ }^{4}$

Todo lo escrito y editado relacionado con la ciencia ficción mexicana durante la última década del siglo anterior resulta ser una preparación extensa para dos estudios pioneros que Trujillo-Muñoz lleva a cabo en el umbral del siglo XXI. En 1999 nuestro autor publica el primero de dichos estudios: Los confines: Crónica de la ciencia ficción mexicana. En un acto virtualmente heroico el autor logra armar una visión panorámica de la ciencia ficción en México desde sus principios en el siglo XVIII hasta nuestros días en una época en la que tales investigaciones eran escazas, por no decir inexistentes. Como observa Miguel Ángel Fernández-Delgado en la introducción a su antología de la ciencia ficción mexicana, Visiones periféricas: Antología de la ciencia ficción mexicana (2001), muchos estudiosos mexicanos creen que no existe la ciencia ficción mexicana o "que está en decadencia, o que es tan mala que más vale no tomarla en cuenta” (Fernández-Delgado, 2001, pp. 13-14). Con este estudio pionero Trujillo-Muñoz comprueba exactamente lo contrario. Nuestro autor comienza su recorrido hablando sobre el texto fundador de la ciencia ficción mexicana (y también de la ciencia ficción latinoamericana): el cuento "Sizigias y cuadraturas lunares" (1775) del Manuel Antonio de Rivas. Por su valor histórico y literario, cabe resumir la trama del dicho relato. Onésimo Dutalon, un francés, inventa una máquina voladora en la cual viaja a la luna donde se encuentra con un congreso de seres lunares quienes están dialogando sobre el contenido de una carta que les ha mandado un habitante de la Península de Yucatán donde explica con números y lógica física cómo llegar a la luna. Dutalon les da un discurso sobre sus métodos científicos y alaba el racionalismo moderno. Al acabar, todos presencian una banda de demonios llevando el alma perdida de un materialista yucateco al sol. Se supone que esta alma condenada es del mismo yucateco que les había mandado la carta a los seres lunares, es decir, el avatar del autor, un cura yucateco, que fue cuestionado por la Santa Inquisición por este escrito "herético" que alaba el racionalismo científico. Este cuento exalta, como observa Trujillo-Muñoz, el método científico, "observación y reflexión, ensayo y crítica" (Trujillo-Muñoz, 1999a, p. 23). Aunque Trujillo-Muñoz no fue ni el que descubrió este cuento perdido ni el que presentó la primera versión paleográfica completa, sí es el primer crítico literario en colocarlo dentro del contexto de la ciencia ficción mexicana por medio de Los confines. ${ }^{5}$

En los siguientes capítulos de Los confines Trujillo-Muñoz expone sobre las obras ya consideradas canónicas de la ciencia ficción mexicana, tales como "La armonía del universo sobre los principios de la armonía física y matemática" (1882) de Juan Nepomuceno-Adorno, "México en el año 1970" (1844) de Fósforo Cerrillos, "Viaje celeste" (1870) de Pedro Castera, El donador de almas (1899) de Amado Nervo (el primer escritor mexicano plenamente dedicado a 
este género literario con varios relatos), Eugenia (1919) de Eduardo Urzaiz-Rodríguez, "Cómo acabó la guerra en 1917” (1917) de Martín Luis Guzmán, Mi tío Juan (1934) de Francisco L. Urquizo, Un hombre más allá del universo (1935) de Dr. Atl (nombre de pluma de Gerardo Murillo), Palamás, Echevete y yo o el lago asfaltado (1945) de Diego Cañedo, "Baby H.P." (1952) de Juan José Arreola, La nueva prehistoria y otros cuentos (1968) de René Rebetez, Mejicanos en el espacio (1968) de Carlos Olvera y Proceso a Faubritten (1976) de Marcela del Río. En toda su exposición Trujillo-Muñoz provee un contexto para colocar las obras en su momento socio-histórico así como breves análisis de las mismas, aunque a veces éstos son sólo tentativos. También, suele incluir citas largas de dichas obras, y lo valioso de esto es que el lector promedio podrá al menos vislumbrar la naturaleza distinta de estos textos poco accesibles. Cabe mencionar que en su entusiasmo por hallar todo texto literario mexicano que pueda ser definido como "ciencia ficción" a veces Trujillo-Muñoz no atina bien. Por ejemplo, a mi ver difícilmente la sección en El perequillo sarniento (1817) de José Joaquín Fernández de Lizardi intitulada "La isla de Saucheofú" califica como ciencia ficción, pues faltan los usos y las consecuencias de la tecnología, aspecto clave de este género literario. Más bien, éste es un relato de la tradición utópica.

En los capítulos posteriores de Los confines nuestro autor se dedica a informarnos sobre el desarrollo de la ciencia mexicana a partir de los años ochenta, comenzando en 1984 con el Concurso de Ciencia Ficción Puebla, iniciado por Celine Armenta. No cabe duda que esta premiación anual ha sido un factor decisivo en promover el interés en este género literario en México, así como en hacer lucir a algunos jóvenes talentosos como Maurcio José Schwartz, José Luis Zárate y Gerardo Horacio Porcayo, entre otros. Trujillo-Muñoz cita a Federico Schaffler-González para quien este premio es "el responsable de la vitalidad que muestra el nuevo movimiento de la ciencia ficción” (Trujillo-Muñoz, 1999a, p. 189). Ramón López-Castro en Expedición a la ciencia ficción mexicana (2000) nota que a partir de la premiación poblana "Las novelas, libros de cuentos y antologías superan con creces toda la producción de CF mexicana realizada antes de 1984" (López-Castro, 2001, p. 141). No obstante, cuando a partir de 1998 a la premiación se agrega la categoría de "fantasía" se contamina la denominación de "ciencia ficción". Otro concurso de la ciencia ficción mexicana que tuvo menos éxito es el Premio Kalpa pues apenas duró seis años, de 1992 hasta 1998. Trujillo-Muñoz se limita a dar la lista de ganadores, que incluyen a Federico Schaffler-González, Pepe Rojo y Gerardo Sifuentes, dejando así que otros cuenten la historia de esta premiación importante. Nuestro autor termina Confines explayando sobre los cuentos, novelas y antologías más conocidos en las vísperas del nuevo siglo, y así el lector se enterará de que la ciencia ficción mexicana estaba y está experimentando un verdadero "boom". Por su calidad documental Confines seguirá siendo por mucho tiempo una obra fundamental de referencia para los eruditos de la ciencia ficción mexicana.

Como si Confines no fuera ya una gran hazaña al delinear la crónica de la ciencia ficción mexicana, un año después en 2000 Trujillo-Muñoz publica su segunda historia sobre el mismo tema, Biografías del futuro: La ciencia ficción mexicana y sus autores. Como observa Berumen, miembro del jurado editorial, este autor "ha aportado al conocimiento de la literatura mexicana uno de los estudios más completos y documentados que existen sobre la ficción especulativa en nuestro país" (Berumen, 2002b, p. 390). En este tomo TrujilloMuñoz organiza la evolución de la ciencia ficción mexicana por medio de cuarenta y dos de sus autores más destacados, comenzando, por supuesto, con Manuel Antonio de Rivas en el 
siglo XVIII y terminando con José Luis Ramírez en el siglo XX. A diferencia de Confines, en este estudio Trujillo-Muñoz profundiza más sobre cada autor o autora al proveer información socio-histórica más detallada que contextualiza las obras bajo consideración. Como en Confines, aquí también hay citas generosas de dichas obras para darnos muestras de los distintos estilos y temáticas de cada autor o autora. En la última sección del libro, intitulada "Anexos", Trujillo-Muñoz ofrece observaciones interesantes sobre la poesía mexicana con la temática cienciaficcionera del viaje espacial (i.e. "Primero sueño" de Sor Juana, "Yo estaba en el espacio" de Amado Nervo), la temática ecologista en la ciencia ficción mexicana, y las escritoras nacionales de este género literario. El autor afirma que en la actualidad el terreno de la ciencia ficción mexicana es aún "movedizo e incierto" (Trujillo-Muñoz, 2000a, p. 353), pero termina con una nota optimista en los albores del nuevo siglo, notando que "los escritores mexicanos de ciencia ficción ya están ingresando a las ligas mayores, nacionales e internacionales" y que "La época del desdén y el ninguneo ha quedado atrás" (Trujillo-Muñoz, 2000a, pp. 361-362). Esta observación de Trujillo-Muñoz es muy acertada, pues es obvio que hoy en día el interés entre los críticos en no sólo la ciencia ficción producida en México sino en toda América Latina sigue aumentando con creces, como se podría notar en la producción creciente de monografías y artículos sobre esta corriente literaria.

En suma, desde hace más de treinta años Gabriel Trujillo-Muñoz ha venido escribiendo, editando y comentando sobre la ciencia ficción mexicana en lo que se puede denominar una tarea casi épica, como he tratado de dejar claro en este ensayo. En un artículo escrito en la entrada al nuevo siglo sobre los escritores mexicanos contemporáneos de terror, fantasía y ciencia ficción, Trujillo-Muñoz nota: "En ellos está la parte más intensa, más estimulante de la narrativa mexicana de nuestros días. En ellos se rescata este espíritu de cambio si entendemos, desde luego, que aquí cambio es sinónimo de mutación, de metamorfosis, de entropía más que de utopía" (Trujillo-Muñoz, 2000b, p. 58). Sin lugar a dudas este escritor mexicalense es un protagonista fundamental en lo que a estas alturas del siglo XXI ha sido, y sigue siendo, claramente un "boom" de la ciencia ficción mexicana. Esta vertiente literaria en las letras mexicanas no es un breve destello casi imperceptible, ni una moda literaria que parecerá en la posteridad una digresión mal aconsejada. Como bien ha demostrado Trujillo-Muñoz, junto con varios otros estudiosos, la ciencia ficción mexicana no es una aberración al lado de las obras canónicas mexicanas ya que -como un pariente distante y desconocido- ha estado con nosotros desde la fundación de esta república. Si toda literatura es un gran salto artístico de la imaginación que al mismo tiempo nos revela las verdades de nuestra existencia cotidiana, entonces las mejores obras de la ciencia ficción también tienen que encontrar cabida dentro de las letras mexicanas.

\section{Notas}

1. También, este cuento puede recordar de la novela apocalíptica de José Agustín, Cerca del fuego (1986), que trata una situación futurista donde México ha sido invadido por los EEUU. Sin embargo, esta obra no es una obra de ciencia ficción como tal ya que la premisa no tiene que ver con los efectos de la tecnología.

2. En su más reciente novela de ciencia ficción, Trenes perdidos en la niebla (2010), Trujillo-Muñoz vuelve a los temas que había tocado en Laberinto: la dictadura, los saltos temporales y la propuesta de una utopía. Esta vez el tirano es el mismo Adolfo Hitler, y la premisa consiste del rescate de los judíos acorralados en trenes con rumbo a campos de concentración. Unas personas en el siglo XXI manipulan el tiempo para que los judíos condenados sean llevados a Baja California en los finales del siglo XIX 
donde este grupo étnico logra integrarse a la nación mexicana como una comunidad trabajadora y tolerante de los demás grupos minoritarios que quieran unirse a ellos, y así se crea una especie de utopía mestiza y multinacional. Pero si existe la posibilidad de cambiar así la historia humana, entonces lo más lógico en este caso sería evitar de una vez que nazca Hitler para que nunca ocurra el Holocausto, por consiguiente, la premisa de esta novela es débil. El tema de la Segunda Guerra Mundial y el nazismo es tratado de manera más llamativa en dos otras novelas ya clásicas de la ciencia ficción mexicana: $E l$ referí cuenta nueve (1943) de Diego Cañedo y Proceso a Faubritten (1976) de Marcela del Río.

3. El título completo del relato de Rivas es: "Syzigias y quadraturas lunares ajustadas al meridiano de Mérida de Yucatán por un anctítona o havitador de la luna, y dirigidas al Bachiller Don Ambrosio de Echeverría, entonador que ha sido de kyries funerales en la Parroquia de el Jesús de dicha ciudad, y al presente profesor de logaríthmica en el pueblo de Mama de la península de Yucatán; para el año del Señor de 1775".

4. Algunas antologías importantes de la ciencia ficción mexicana que siguieron la de Trujillo-Muñoz incluyen: Los mapas del caos (1997), Silicio en la memoria (1998) y El hombre en las dos puertas: un tributo de la ciencia ficción mexicana a Phillip K. Dick (2002), las tres editadas por Gerardo Horacio Porcayo; Visiones periféricas: Antología de la ciencia ficción mexicana (2001), editada por Miguel Ángel Fernández-Delgado; y Los viajeros; 25 años de ciencia ficción en México (2010), editada por Bernardo Fernández ("Bef”).

5. En su artículo "The Birth of Science Fiction in Spanish America” (2003, Science Fiction Studies, Vol. 30) Aaron Dziubinskyj explaya de manera detallada sobre este cuento de Manuel Antonio de Rivas.

\section{Bibliografía}

Amis, K. (1976). Starting Points. Por M. Rose (Ed.). Science Fiction: A Collection of Critical Essays. (9-29). Englewood Cliffs: Prentice-Hall.

Agustín, J. (1996). Cerca del fuego. México, D.F.: J. Mortiz.

Berumen, H.F. (2002a). As times by o las trampas de la derridación. Por R.M. EspinozaGalindo (Comp.). Gambusino de las letras: Textos en torno a la vida y obra de Gabriel Trujillo Muñoz (1981-200). (291-294). Mexicali: Lito-Impremex.

Berumen, H.F. (2002b). Biografías del futuro. Por R.M. Espinoza-Galindo (Comp.). Gambusino de las letras: Textos en torno a la vida y obra de Gabriel Trujillo Muñoz (1981-2001). (389-390). Mexicali: Lito-Impremex.

Berumen, H.F. (2002c). Miríada, de Gabriel Trujillo Muñoz. Por R.M. Espinoza-Galindo (Comp.). Gambusino de las letras: Textos en torno a la vida y obra de Gabriel Trujillo Muñoz (1981-2001). (207-208). Mexicali: Lito-Impremex.

Cañedo, D. (1943). El Réferi cuenta nueve. México, D.F.: Editorial Cultura.

Crichton, M. (1990). Jurassic Park. New York: Random House.

Del Río, M. (1976). Proceso a Faubritten. México, D.F.: Editorial Aguilar.

Dziubinskyj, A. (2003). "The Birth of Science Fiction in Spanish America". Science Fiction Studies. 30 (1), 21-32.

Espinoza-Galindo, R.M. (2002). Gabriel Trujillo Muñoz: La lengua del camaleón. Por R.M. Espinoza-Galindo (Comp.). Gambusino de las letras: Textos en torno a la vida y obra de Gabriel Trujillo Muñoz (1981-2001). (11-19). Mexicali: Lito-Impremex.

Fallon, P. (2002a). Entre Laberinto y Mesquite Road. Por R.M. Espinoza-Galindo (Comp.). Gambusino de las letras: Textos en torno a la vida y obra de Gabriel Trujillo Muñoz (1981-2001). (92-94). Mexicali: Lito-Impremex. 
Fallon, P. (2002b). Supplementing Time on the Border: Gabriel Trujillo Muñoz's Laberinto and Mesquite Road and Border Theories. Por R.M. Espinoza-Galindo (Comp.). Gambusino de las letras: Textos en torno a la vida y obra de Gabriel Trujillo Muñoz (1981-2001). (374-381). Mexicali: Lito-Impremex.

Fernández, B. [El Bef]. (Ed.). (2010). Los viajeros, 25 años de ciencia ficción mexicana. México: Ediciones SM.

Fernández-Delgado, M.A. (2001). Visiones periféricas: Antología de la ciencia ficción mexicana. Buenos Aires: Grupo Editorial Lumen.

López-Castro, R. (2001). Expedición a la ciencia ficción mexicana. México, D.F.: Editorial Lectorum.

Lem, S. (1961). Solaris. Warszawa: Wydawn, Ministerstwa Obrony Narodowej.

Porcayo, G.H. (Ed.).(1997). Los mapas del caos. México: Ramón Llaca.

Porcayo, G.H. (Ed.). (1998). Silicio en la memoria. México: Ramón Llaca.

Porcayo, G.H. (Ed.). (2002). El hombre en las dos puertas: un tributo de la ciencia ficción mexicana a Phillip K. Dick. México, D.F.: Editorial Lectorum.

Shelley, M. (1999). Frankenstein. Ontario: Broadview Press.

Stavans, I. (2002). Una ventana abierta a la ciencia ficción. Por R.M. Espinoza-Galindo (Comp.). Gambusino de las letras: Textos en torno a la vida y obra de Gabriel Trujillo Muñoz (1981-2001). (200-202). Mexicali: Lito-Impremex.

Trujillo-Muñoz, G. (1991a). La ciencia ficción. Literatura y conocimiento. Mexicali: Instituto de Cultura de Baja California.

Trujillo-Muñoz, G. (1991b). Miríada. Mexicali: Larva.

Trujillo-Muñoz, G. (1995). Laberinto (As times goes by). Mexicali: Instituto de Cultura de Baja California.

Trujillo-Muñoz, G. (1997). El futuro en llamas: cuentos clásicos de la ciencia ficción mexicana. México, D.F.: Grupo Editorial Vid.

Trujillo-Muñoz, G. (1999a). Los confines: Crónica de la ciencia ficción mexicana. México, D.F.: Grupo Editorial Vid.

Trujillo-Muñoz, G. (1999b). Espantapájaros. México, D.F.: Editorial Lectorum.

Trujillo-Muñoz, G. (2000a). Biografías del futuro: La ciencia ficción mexicana y sus autores. Mexicali: Universidad Autónoma de Baja California.

Trujillo-Muñoz, G. (2000b). Los cuentos del lado oscuro (Terror, fantasía y ciencia ficción en México). Tierra Adentro. 140, 57-63.

Trujillo-Muñoz, G. (2010). Trenes perdidos en la niebla. México, D.F. Editorial Jus.

Trujillo-Muñoz, G. (s.f.). La ciencia ficción mexicana: atisbos para su historia. [Ensayo inédito].

Trujillo-Muñoz, G. (s.f). ¿Qué me inspiró a escribir y estudiar la ciencia ficción?. [Ensayo inédito]. 
Verne, J. (1918). From the Earth to the Moon. New York: Scribner.

Wells, H.G. (2001). The War of the Worlds. Jefforson: McFarland.

Yépez, Heriberto. (2002). Ciencia ficción, espantapájaros y chupacabras. Por R.M. EspinozaGalindo (Comp.). Gambusino de las letras: Textos en torno a la vida y obra de Gabriel Trujillo Muñoz (1981-2001). (324-327). Mexicali: Lito-Impremex. 
